\title{
KAZAKİSTAN'DA BULUNAN KOYTUBEK YAZITINDA KÖKTÜRK YAZISININ ADI GEÇIYOR MU?
}

\section{Nurdin USEEV ${ }^{*}$}

$\ddot{O} \mathbf{z}$

$\mathrm{Bu}$ makalede Kazakistan'da bulunan yazıtlardan Koytubek Yazıtı ele alınarak üzerinde okuma ve anlamlandırma teklifli yapılmıştır. Çünkü söz konusu yazıt üzerinde İ. L. Kızlasov'un yaptığı okuma ve anlamlandırma çalışmasına göre bu yazıtta Köktürk yazısının Köktürkçe adı geçmektedir. Dolayısıyla Köktürk yazıt bilimi açısından büyük önem arz etmektedir. Bundan nedenle söz konusu yazıt üzerindeki çalışmaları değerlendirmek ve bu görüşün doğru olup olmadığı konusunda kendi görüşümüzü ifade etmek istedik. Çalışma sonucunda araştırma ve incelemeye konu olan yazıttaki bazı kelimelerin yanlış okunduğu ya da yanlış anlaşıldığı tespit edilerek uygun olduğu düşünülen okunuşlar ve anlamlandırmalar ileri sürülmüşsür. Örneğin, bugüne kadar değişik şekilde okunarak 'yazı, adı' olarak anlamlandırılan EYl| k kelimesi 'b(e)ş(i)kl(i)g' ş̧eklinde okunmuştur. Yazııın tamamı 'b(e)ş(i)kl(i)g yurtım' şeklinde okunmuş ve 'beşikli (ana, öz) yurdum' diye anlamlandırılmıştır. Bir başka deyişle İ. L. Kızlasov tarafından ileri sürülen görüşe hiç uyum göstermeyen okuyuş ve anlamlandırma ortaya çıkmıştır.

\section{Anahtar Sözcükler: Kazakistan yazıtları, Koytubek Yazıtı, kaya, beşik, yurt. \\ DOES IS PASSING THE NAME OF KÖKTÜRK WRITING ON THE KOYTUBEK INSCRIPTION FOUND IN KAZAKHSTAN?}

\begin{abstract}
In this article was made reading and explaining bids on the Koytubek Inscription from Kazakhstan. Because according to the İ. L. Kizlasov's study and interpretation on this inscription in the Koytubek Inscription passes Kokturkish name of Köktürk writing. Therefore, this inscription has an of great importance in terms of Köktürk epigraphy. Therefore, we want to to evaluate the works on this inscription and to express our own opinion about whether it this view is correct. End of study it was determined that some of the words of inscription, which is the subject for our research and study read or misunderstood wrong before. And have been suggested considered suitable explanations and readings. For example, the word EY기소 have been read as different forms and interpreted as 'writing, name'. But end of our study was stated that this word read as ' $b(e)$ ş(i)kl(i)g'. The full inscription have been read as 'b(e)ş(i)kl(i)g yurtım' and interpreted as ' my cradle (native) land'. In other words, has emerged the readings and meaning which showing no compliance İ. L. Kizlasov's opinion.
\end{abstract}

Keywords: Inscription of Kazakhstan, Koytubek Inscription, rock, cradle, homeland.

\footnotetext{
Yrd. Doç. Dr.; Kırgızistan-Türkiye Manas Üniversitesi, Edebiyat Fakültesi, Türkoloji Bölümü, nuruseev@gmail.com.
} 


\section{Ø. Giriş:}

Bugüne kadar Kazakistan'da otuza yakın yazıt bulunmuştur. Bu yazıtların büyük bir kısmı kayalara kazınmış küçük yazıtlardır. Biz bu makalemizde 1985 yılında A. E. Rogojinski tarafından bulunan, ancak 2008 yılından itibaren üzerinde araştırmalar yapılmaya başlanan Koytubek Yazıtı'nı okumaya ve anlamlandırmaya çalıştık. Çünkü yazıtın önceki okunuşlarında ve anlamlandırmalarında bazı eksikliklerin olduğunu düşünmekteyiz. Üstelik İ. L. Kızlasov tarafından ileri sürülen okuma ve anlamlandırmaya göre bu yazıt Köktürk yazısının adlandırılmasının yazıtlardaki tek örneğini barındırmaktadır. Yani Köktürk yazıt bilimi açısından büyük bir ilgi uyandırmaktadır. Dolayısıyla yazıt üzerinde yapılan okuma ve anlamlandırma tekliflerini yeni verilerin ışığında yeniden gözden geçirmek önem kazanmaktadır.

\section{Yazıt Hakkında Genel Bilgi ve Önceki Okuyuşlar:}

Söz konusu yazıt, 1985 y1lında Doğu Kazakistan'da, Kurçum dağ zincirlerinin güneydoğu tarafindaki Koytubek arazisinde A. E. Rogojinski tarafindan bulunmuştur. Daha sonra 2008 yılında yine adı geçen arkeolog tarafından yeniden bulunarak bilim dünyasına duyurulmuştur. "Uzunluğu $50 \mathrm{~cm}$ olan dikey bir satırdan ve yükseklikleri $5-9 \mathrm{~cm}$ arasında değiş̧en 12 harften oluşan bu yazıt bugün bulunduğu yerdedir” (Rogojinski, 2010: 331).

Söz konusu yazıt, A. S. Amancolov, İ. L. Kızlasov, S. E. Klyaştornıy ve N. Bazılhan tarafından okunmuş ve anlamlandırılmıştır.

Ele alınan yazıt, A. S. Amancolov tarafindan ‘ $\Upsilon \hat{\wedge} 4>D S E Y S D$ ((a)j (a) (ä)l(i)g(a)jurtï; aj elig jurtı)' şekinde okunarak “Ay hükümdarının (Ay Elig) yurdu (Stanovişe Lunnogo pravitelya (Ay-Elig))" diye tercüme edilmiştir (Amancolov, 2003: 204).

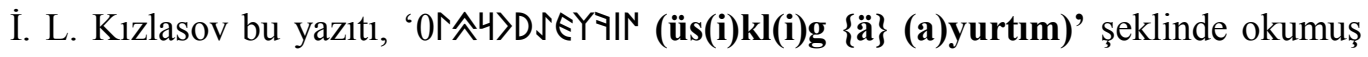
ve "Yazılı şekilde konuşmasını söyledim ( $Y a$ velel izyasnyatsya pis'menno)" diye anlamlandırmıştır (Kızlasov, 2011: 65).

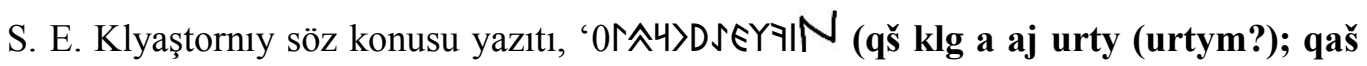
külüg : aj urty (urtym?))' şeklinde okuyarak “Kaş Külüg (ya da: Ben, Kaş Külüg?) (kayaya) ay kazıdım (Kaş Külüg (ili: Ya, Kaş Külüg?) vırezal (na skale) lunu” diye anlamlandırmaktadır (Klyaştornıy, 2012: 45).

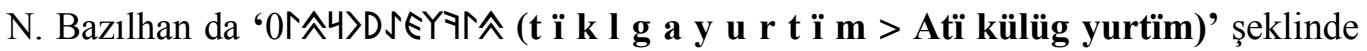
okumuş ve " $A d l$ / ismi / meşhur yurdum, ocağım” diye anlamlandırmıştır (Bazılhan, 2014: 4). 


\section{Yazıt Üzerinde Yeni Okuma ve Anlamlandırma Teklifi:}

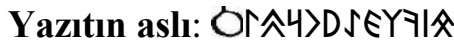

Okunuşu: b(e)ş(i)kl(i)g a yurtım

Tercümesi: Beşikli (ana, öz) yurdum (vatanım).

\subsection{Yazit Üzerinde Okuma Denemesi:}

Yeni bir okuma ve anlamlandırma denemesinde bulunmadan önce daha önce ileri sürülen okuyuş ve anlamlandırmaları ele almak gerekmektedir. Önceki okuyuşlarda tartışmalı olan harfler ilk harflerdir. A. S. Amancolov yazıtın 10 harften oluştuğunu düşünerek ilk ve son harfi okumamıştır. Daha sonraki ikinci ve üçüncü harflerin $D$ ve $\checkmark$ harfleri olduğunu belirtmektedir (Amancolov, 2003: 203-204). Daha sonra İ. L. Kizlasov, A. S. Amancolov tarafından D harfi olarak kabul edilen ve yazıtın ikinci harfi olan işareti, genel olarak ince ünlülerle geçen s sesini, bazen de ş sesini bildiren I harfi olarak düzeltmiştir. S. G. Klyaştornıy da bu harfi I harfi olarak kabul etmektedir (Klyaştornıy, 2012: 45). N. Bazılhan ise i, I ünlülerini bildiren $\uparrow$ harfi olarak okumaktadır (Bazılhan, 2014: 4). Ancak yazıtın değişik resimlerine baktığımızda hepsinde bu işaretin I harfi olduğu açıkça görülmektedir. A. S. Amancolov tarafından $\checkmark$ harfi olarak kabul edilen ve yazıtın üçüncü harfi olan işaret daha sonra bu yazıt üzerinde çalışan bilim adamlarının tamamı tarafından ince ünlülerle geçen $\mathbf{k}$ sesini yansıtan $\mathbf{7}$ harfi olarak düzeltilmiştir.

İlk harf A. S. Amancolov tarafindan okunmamıştır (Amancolov, 2003: 203-204). I. L. Kızlasov bu harfi ö, ü ünlülerini yansitan $\mathbf{N}$ harfi olarak yorumlamaktadır (Kızlasov, 2011: 65). S. G. Klyaştornıy bu görüşe katılmayıp, $\mathbf{N}$ harfinin bu şekildeki kullanımının Talas yazıtlarında görülmediğini gerekçe olarak göstererek Talas yazıtlarında kalın ünlülerle geçen $\mathbf{k}$ sesini

bildiren $N$ harfi olarak okumaktadır (Klyaştornıy, 2012: 45). N. Bazılhan ise bu harfin ses değerini t olarak yorumlamaktadır (Bazılhan, 2014: 4). Herhalde N. Bazılhan, A. E. Rogjinski'nin estampajlı çiziminde bu harfin üstünde iki yatay çizgi bulunduğuna dikkat ederek kalın ünlülerle geçen $\mathbf{t}$ sesini bildiren $\hat{\boldsymbol{A}}$ harfi olarak görmektedir. Bunlardan A. S. Amancolov'un fikrini kabul etmek mümkün değildir. Çünkü bu işaretin y sesini bildiren $\mathbf{D}$ harfi olmadığı çok açıktır. S. G. Klyaştornıy’ın görüşüne gelirsek bu harfi kalın ünlülerle geçen $\mathbf{k}$ sesini bildiren $N$ harfi olarak okumak zor görünmektedir. Çünkü bundan sonra gelen ve hem $\mathbf{s}$ hem de ş sesini bildiren I harfi yazıtlarda, onun içinde Talas yazıtlarında daha çok ince ünsüz işaretleriyle birlikte geçmektedir. Söz konusu harfi kalın ünlülerle geçen $\mathbf{k}$ sesini bildiren $N$ harfi olarak kabul ederek 'kaş' şeklinde okuyabilmek için bundan sonra Talas yazıtlarında olduğu gibi $\rtimes$ harfi bulunmalıydı. N. Bazılhan'ın kalın ülülerle geçen $\mathbf{t}$ sesini bildiren $\boldsymbol{\wedge}$ harfi 
olarak kabul edip daha sonraki harf ile birlikte ' $a d$, ismi' anlamına gelen '(a)tı' kelimesi şeklinde okuması bize göre yanlıştır. Çünkü bu harften sonraki işaretin 1 , i ünlülerini bildiren $\Gamma$ harfi değil, hem s hem de ş sesini bildiren I harfi olduğu çok açıktır. Dolayısıyla geride İ. L. Kızlasov'un okuyuşu kalmaktadır. Adı geçen bilim adamı bu harfi ö, ü ünlülerini yansıtan $\mathbf{N}$ harfi olarak yorumlayarak ㅋN şeklinde gördüğü harfler kümesinin tamamını 'yazı' anlamına gelen 'üşik' kelimesi olarak okumaktadır (Kızlasov, 2011: 65). Ancak bu kelimeyi 'yazı' anlamına gelen 'üşik' kelimesi olarak okumak için birkaç zorluk bulunmaktadır. İlk önce İ. L. Kızlasov'un kendisi de belirttiği gibi 'yazı' anlamına gelen kelime 'üzük / üzik' şeklindedir. İ. L. Kızlasov Çağataycadaki üşikle- fiilinden hareketle $\mathbf{z}$ sesinin ş sesine dönüştüğünü düşünmektedir (Kızlasov, 2011: 72). Ancak $\mathbf{z}$ sesinin $\mathbf{s}$ sesine dönüştüğü örnekler yazıtlarda görülmemektedir. $\mathbf{Z}$ sesinin kelime içinde ş sesine dönüştüğü Türk dilinin tarihî dönemlerinde görülmez. $\mathbf{Z}$ sesinin kelime sonunda ötümsüzleşerek ş sesine benzeyen $\mathbf{s}$ sesine dönüşmesi Çağatayca ve Kıpçak Türkçelerinden itibaren görülür: kelmez > kelmes (Karaağaç, 2012: 227231). Bundan başka İ. L. Kızlasov yazıttaki ikinci kelimeyi '(a)yurtım' şeklinde okuyup, 'söylemek, konuşmak' anlamına gelen 'ay-' fiiline ettirgenlik eki eklenmiş bir kelime olarak açıklamaktadır (Kızlasov, 2011: 65). Buna S. G. Klyaştornıy haklı olarak itiraz etmiştir (Klyaştornıy, 2012: 45). Gerçekten de Eski Türkçede 'ay-' fiil kökünün ettirgenlik eki 'aytur-' şeklindedir (Nadelyayev vd., 1969: 30-31). Dolayısıyla içerik bakımından bizim için değerli olmasına rağmen bu okuyuşa kuşkuyla bakmamız gerekmektedir. Üstelik yazıtın estampajlı çizimi ve başka resimleri yazıttaki bu harfi değişik şekilde okumak için olanak sağlamaktadır. Yazıtın Alan Baytenov tarafından yapılan son fotoğrafına bakıldığında ilk harfin ince ünlülerle geçen b sesini bildiren harfi olduğu görülmektedir (Foto 1, Çizim 1). Bundan başka yazıtın A. E. Rogojinski tarafından yapılan estampajlı çiziminde bu harfin üstünde iki yatay çizgi görülmektedir (Çizim 2) ${ }^{1}$. Dolayısıyla yazıtın genel anlamını, önceki okuyuşlardan mantıklı sonuçlar elde edilmediğini ve en önemlisi yazıtın yeni resmini dikkate alarak bu işaretin ince ünlülerle geçen b sesini bildiren harfi olduğunu düşünmekteyiz. Söz konusu harfi bu şekilde okumak daha sonra gelen ve ince ünlülerle geçen s sesini, bazen de ş sesini bildiren I harfiyle birlikte okunması için de olanak sağlamaktadır. Böylece yazıtın başlangıcı olan EY‡|ર harfler kümesini 'b(e)ş(i)kl(i)g' şeklinde okuyup bu kelimenin harfiyen 'beşikli' anlamına geldiğini, ancak yazıtta mecazi anlamda kullanıldığını düşünmek mümkündür.

Yazıt ortasındaki $\checkmark$ harfi İ. L. Kızlasov’un belirttiği gibi kelimeleri ayırt edici bir işarettir.

\footnotetext{
${ }^{1}$ Bundan dolayı N. Bazılhan söz konusu işareti kalın ünlülerle geçen $\mathbf{t}$ sesini bildiren $\hat{\boldsymbol{A}}$ harfi olarak görmektedir.
} 
Oイヘ4〉D harfler kümesinin 'yurdum, vatanım' anlamına gelen 'yurtım' kelimesi olduğunda hiç şüphe yoktur. Çünkü ${ }^{\circ}$ harfi Talas yazıtlarında m sesini yansıtmaktadır (Alimov, 2013: 21).

\subsection{Yazıt Üzerinde Anlamlandırma Denemesi:}

Yazıt 'b(e)ş(i)kl(i)g' ve 'yurtım' şeklindeki iki kelimeden oluşmaktadır. 'Yurtım' kelimesinin kökü 'yurt, vatan' anlamına gelen 'yurt' kelimesi olup, +ım 1. şahıs iyelik ekidir. 'Yurtım' kelimesi 'vatanım, yurdum' anlamında Yenisey yazıtlarından Ald1-Bel II (E 72) yazıtında da geçmektedir: kırıg yurtım (Kırıg yurdum (vatanım)) (Useev, 2011: 560).

'Beşiklig' kelimesinin kökü 'beşik' kelimesidir. +lig ise genellikle 'sahip' olan anlamına gelen sifatlar yapan bir isimden isim yapma ekidir (Alyılmaz, 1994: 15; Kononov, 1980: 106; Tekin, 2003: 83). 'Beşik' kelimesi Eski Türkçede 'beşik' anlamına gelmektedir (Nadelyayev vd., 1969: 97). Bununla birlikte 'beşiklig' kelimesi Divanü Ligat-it-Türk'te 'beşiklig uragut' tabirinde 'beşikli, emzikli' anlamında geçmektedir (DLT, I, 509). Bize göre 'beşiklig' kelimesi ele alınan yazıtta 'beşikli' şeklindeki düz anlamında değil, mecazi anlamda 'ana, öz, doğup büyüyen' anlamlarına gelmektedir. Bundan hareketle 'b(e)ş(i)kl(i)g yurtım' şeklindeki yazıtın 'ana, öz vatan' anlamına geldiğini düşünüyoruz. 'Beşik' kelimesi bugünlerde Türk halklarında yer adlarında çok kullanılan ve vatan, ana vatan anlamını taşıyan kelimelerden birisidir. Örneğin, Kırgızcada doğup büyüdüğü yurdunu belirtmek için 'altın beşigim' tabiri kullanılır (Yudahin I, 1985: 133).

İ. L. Kızlasov Köktürk harfli yazıtları, daha netleştirirsek Yenisey yazıtlarını içerik bakımından 12 alt türe ayırmaktadır: 1. Epitafiler, 2. Sınır Yazıtları, 2. Ad (İsimlendirme) Yazıtları, 4. Dua Yazıtları, 5. Tören ve ayin yazıtları, 6. İtiraf-Kendisini Aşağı Görme Yazıtları, 7. Övme Yazıtları, 8. Ziyaretçi Yazıtları, 9. Büyü-Afsun Yazıtları, 10. Açıklama Yazıtları, 11. Aidiyet Yazıtları ve 12. İyi Dilek Yazıtları (Kızlasov, 1994: 180-203). Ele alınan yazıt içerik bakımından bulunduğu yerin, toprağın belirli bir özelliğini belirten açıklama yazıtlara benzemektedir. Çünkü bu yazıtta, yazıtın bulunduğu yerin yazıtı yazan kişi için ana vatan, doğup büyüdüğü yurt olarak ifade edildiği görülmektedir.

\section{Sonuç:}

Bizim yaptığımız çalışma sonucunda söz konusu yazıtın ilk harfinin okunuşunda bazı sorunların olduğu ortaya çıkmıştır. Bundan dolayı yazıtın ilk kelimesi bilim adamları tarafından değişik şekilde okunmuş ve anlamlandırılmıştır. Yazıtın estampajlı çiziminde ve yeni fotograflarında daha önce $\ddot{\mathbf{u}}$, $\mathbf{o}$ seslerini bildiren $\mathbf{N}$, kalın ünlülerle geçen $\mathbf{k}$ sesini bildiren $\mathbf{N}_{\text {ve }}$ kalın ülülerle geçen $\mathbf{t}$ sesini bildiren $\boldsymbol{\wedge}$ harfi olarak yorumlanan işaretin ince ünlülerle geçen $\mathbf{b}$ 
sesini bildiren $\mathbf{x}$ harfine benzediği görülmektedir. Dolayısıyla bu işaretin yanındaki harflerin özelliğine, yani ince ünlülerle geçen ünsüz sesleri bildiren harflerin bulunduğuna ve yazıtın anlamına dikkat ederek yazıtın ilk harfinin ince ünlülerle geçen b sesini bildiren $\mathbf{x}$ harfi

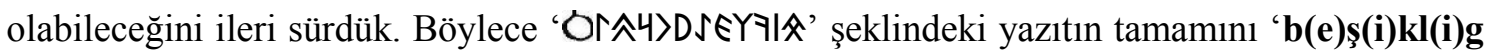
yurtım' diye okuyup 'Beşikli (ana, öz) yurdum (vatanım)' şeklinde anlamlandırdık.

\section{Kaynaklar}

ALiMOV, R. (2013). Tanrı Dağı Yazıtları: Eski Türk Runik Yazıtları Üzerine Bir İnceleme. Konya: Kömen Yayınları.

ALYILMAZ, C. (1994). Orhun Yazıtlarının Söz Dizimi. Erzurum.

AMANCOLOV, A. S. (2003). İstoriya i Teoriya Drevnetyurkskogo Pis'ma. Almat1.

BAZILHAN, N. (2014). Kazakistan'da Bulunan Göktürk Yazıtları Hakkında. Uluslararası Türkçe Edebiyat Kültür Eğitim Dergisi, 3(2), 1-12,

Divanü Ligat-it-Türk Tercümesi I, II, III, IV. (4. Bask1). (1998). Ankara: Türk Dil Kurumu Yayınları. (çev. Besim Atalay).

KARAAĞAÇ, G. (2012). Türkçenin Ses Bilgisi. İstanbul: Kesit Yayınları.

KIZLASOV, İ. L. (1994). Runiçeskya Pis'mennost' Evraziyskih Stepey. Moskova.

KIZLASOV, İ. L. (2011). Kak Nazıvali Runiçeskoye Pis'mo Sami Tyurkskiye Narodı. Rossiyskaya Tyurkologiya, 2(5), 62-74.

KONONOV, A. N. (1980). Grammatika Yazıka Tyurkskih Runiçeskih Pamyatnikov (VII-IX vv.). Leningrad.

NADELYAYEV vd. (1969). Drevnetyurkskiy Slovar'. Leningrad.

ROGOJINSKİ, A. E. (2010). Novıye Nahodki Pamyatnikov Drevnetyurkskoy Epigrafiki i Monumental'nogo İskusstva na Yuge i Vostoke Kazahstana. Rol' Nomadov v Formirovanii Kul'turnogo Naslediya Kazahstana. Almat1. 329-344.

TEKİN, T. (2003). Orhon Türkçesi Grameri. İstanbul.

USEEV, N. (2011). Yenisey Cazma Estelikteri I: Leksikası cana Tekstter (Yenisey Yazıtları I: Söz Varlığl ve Metinler). Bişkek.

YUDAHIN, K. K. (1985). Kirgizsko-Russkiy Slovar'. Frunze. 


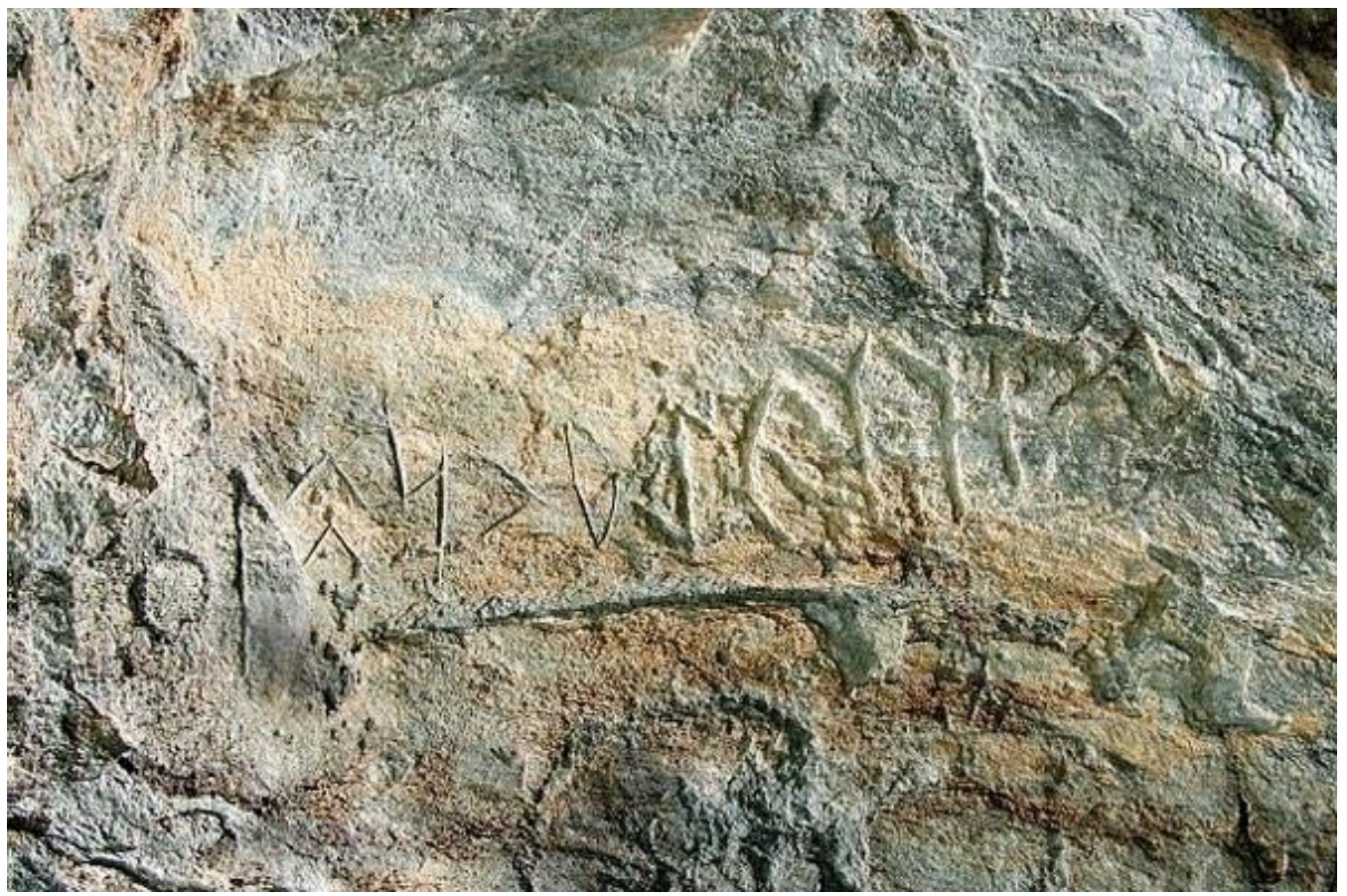

foto 1: Koytubek Yazıtı (Alan Baytenov)

(http://www.np.kz/2013/07/26/print:page, 1,tolkovanie slov.html) )

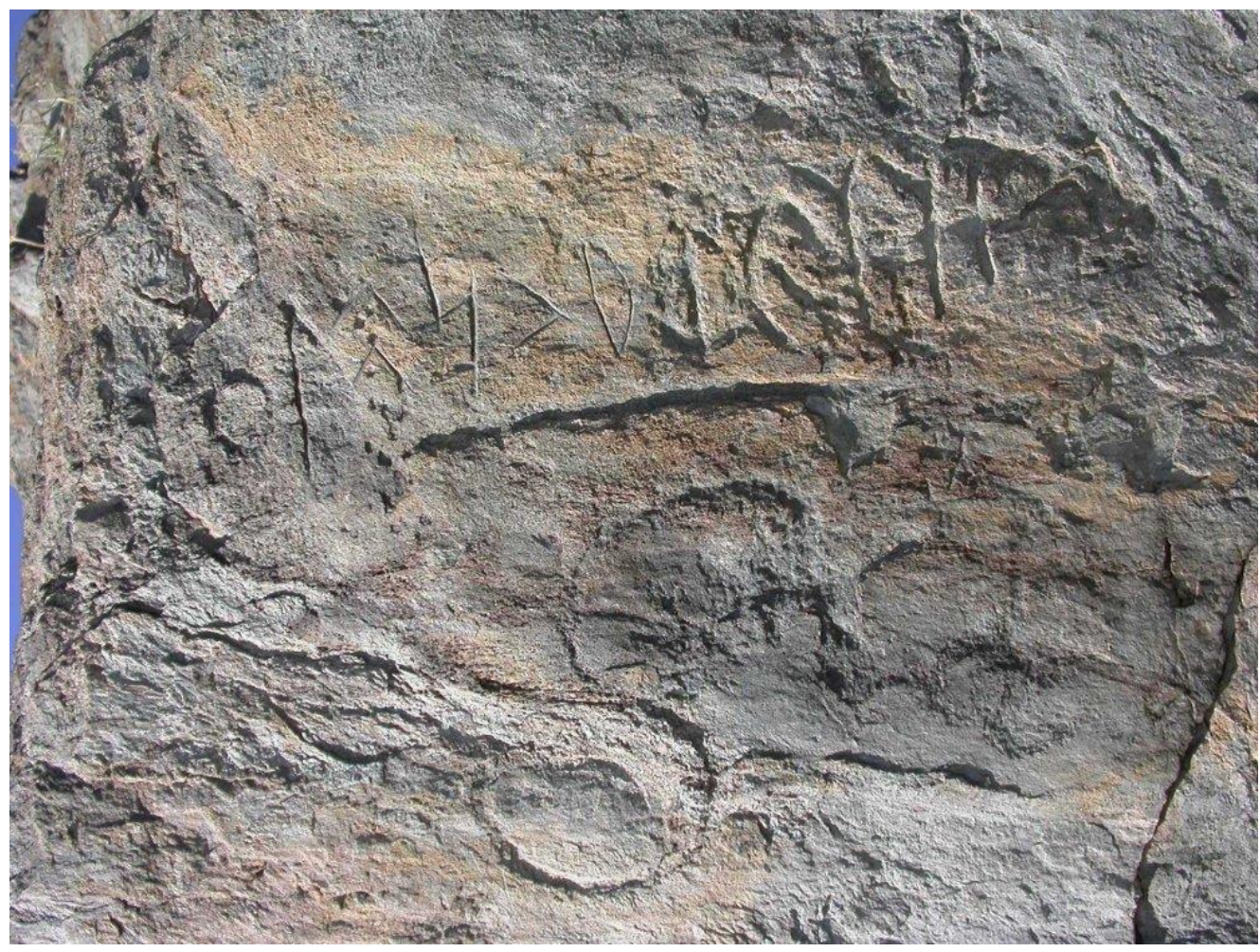

foto 2: Koytubek Yazıtı (A. E. Rogojinski)

TरFp 


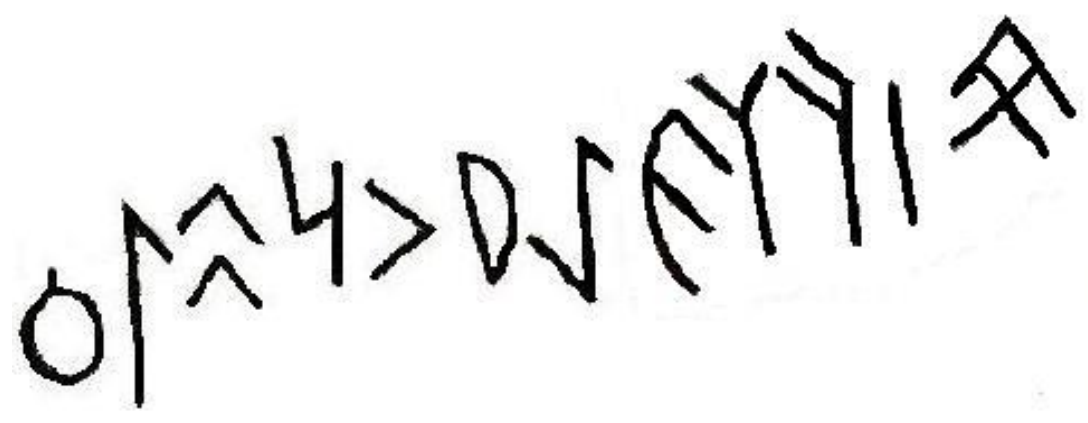

çizim 1: Koytubek Yazıtı'nın çizimi (Alan Baytenov'un resmine göre N. Useev)

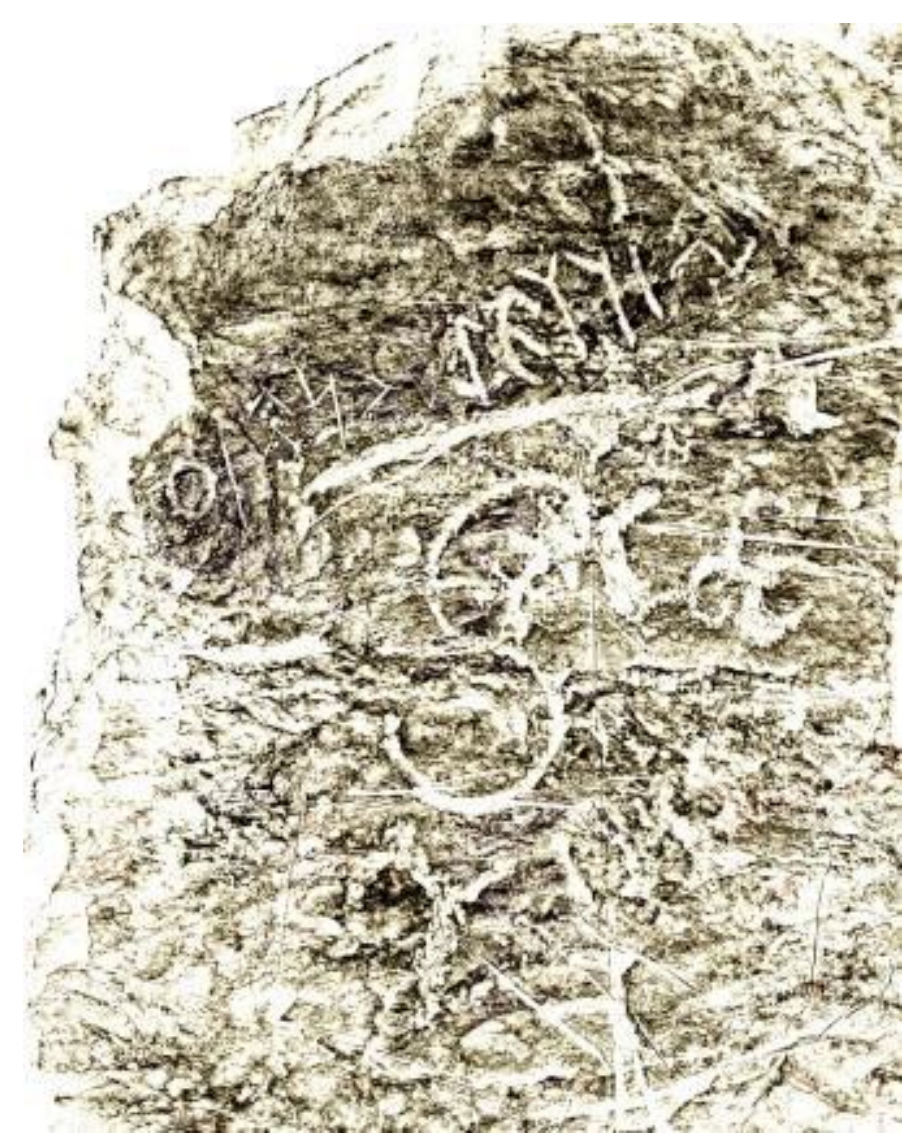

çizim 2: Koytubek Yazıtı'nın estampajlı çizimi (A. E. Rogojinski) 


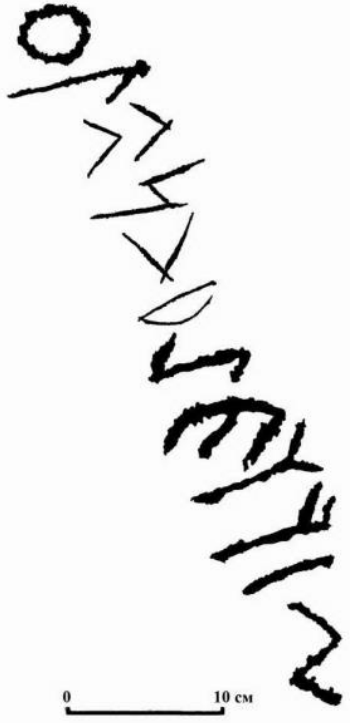

çizim 3: Koytubek Yazıtı'nın çizimi (A. E. Rogojinski)

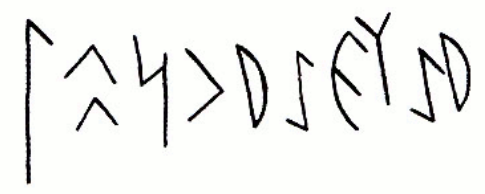

çizim 4: Koytubek Yazıtı'nın çizimi (A. S. Amancolov) 